\title{
Erweiterung des Treuhandpartnernetzes im Kanton Schwyz
}

Die Wirtschafts-Treuhand AUCTOR SCHWYZ AG, die neue Vertrauenspartnerin FMH Services (Treuhand), ist eine eigentümergeführte Treuhand- und Wirtschaftsprüfungsgesellschaft mit Sitz in Schwyz und Wollerau, welche seit über 40 Jahren Unternehmer/innen und Unternehmen mit Buchführungs-, Sozialversicherungs-, Steuer- und Rechtsberatung unterstützt.

Die Schwerpunkte der Tätigkeiten liegen einerseits in den Bereichen Finanz- und Rechnungswesen, Unternehmensberatung, Wirtschaftsprüfung, Personalvorsorgeberatung und andererseits in den Bereichen Steuer- und Rechtsberatung wie auch Beurkundungen (z.B. bei Firmengründungen, Statutenänderungen, Erb- und Eheverträgen).
Grundlage für die erfolgreiche Beratung sind der persönliche Kontakt und ein gegenseitiges Vertrauensverhältnis zwischen Auftraggebern und Beratern. Darauf sind unsere Arbeitsmethoden ausgerichtet. Wir schaffen durch persönliche Besprechungen Klarheit über die Aufgabenstellung, die anfallenden Probleme und den ungefähren Zeitaufwand. Die Ausführung des Auftrags geschieht in enger Zusammenarbeit mit den Auftraggebern.

Unser Grundsatz ist die fachgerechte, objektive und einwandfreie Beratung der Auftraggeber, unbesehen der Grösse des Auftrags und abgestimmt auf die Lebensphase, in welcher sich die Unternehmer/innen befinden.

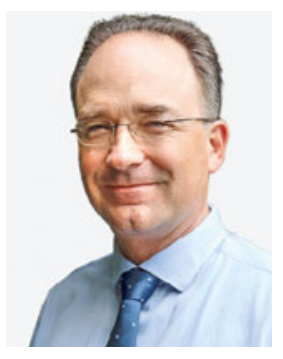

Patrick von Reding

lic. oec. HSG (Universität St. Gallen) patrick.vonreding@fmhtreuhand.ch

$\begin{array}{ll}\text { Standort Schwyz } & \text { Standort Wollerau } \\ \text { Wirtschafts-Treuhand } & \text { Wirtschafts-Treuhand } \\ \text { AUCTOR SCHWYZ AG } & \text { AUCTOR SCHWYZ AG } \\ \text { FMH Services (Treuhand) } & \text { FMH Services (Treuhand) } \\ \text { Oberer Steisteg 18 } & \text { Färberstrasse 4 } \\ \text { 6430 Schwyz } & 8832 \text { Wollerau } \\ \text { Tel. 0418115752 } & \text { Tel. 044 687 32 30 } \\ \text { Fax 0418117703 } & \text { Fax 041811 77 03 }\end{array}$

Die Wirtschafts-Treuhand AUCTOR SCHWYZ AG ist ein von der FMH Services Genossenschaft empfohlenes, rechtlich und wirtschaftlich selbstständiges Beratungsunternehmen.

\section{Mehrwertsteuerprobleme?}

\section{ந. FMHSERVICES}

«Medizinische Leistungen sind nicht mehrwertsteuerpflichtig!» Diese Aussage ist zwar richtig, jedoch nicht in jedem Fall. In Doppel- und Gruppenpraxen sowie bei Selbstdispensation sollte die Mehrwertsteuerthematik genau abgeklärt werden. Die Vertrauenspartner FMH Services (Treuhand) sind Ihre Spezialisten. Nutzen Sie unser Know-how. 